\title{
Development of Artificial Neural Network Model for Permeability of High Performance Concrete
}

\author{
Dr. H. Sudarsana Rao
}

\begin{abstract}
High performance concrete (HPC) is an engineered concrete possessing the most desirable properties during fresh as well as hardened concrete stages. Permeability is one of the most important parameters to quantify the durability of high-performance concrete. This research was to study the chloride ion permeability of high performance concrete with different mineral admixtures like Fly ash, Silicafume and Metakaolin of different percentages, with varying aggregate-binder ratios $(2,2.5)$. In addition, on the basis of the experimental data an artificial neural network (ANN) technique is executed to demonstrate the possibilities of artificial neural network formulation for the prediction of chloride permeability as a function of four input parameters : water-cement ratio $(0.3,0.325,0.35,0.375,0.4,0.425,0.45$, $0.475,0.5)$, aggregate binder ratio $(2,2.5)$, type of mineral admixtures, percentage replacement of mineral admixtures i.e Fly ash, Silicafume and Metakaolin $(0,10,20,30 \%)$ as input parameters. Genetic algorithm has been used to extract the weights of ANN model. The developed model is able to predict the permeability within $5 \%$ error.
\end{abstract}

Keywords - HPC, Genetic Algorithm, ANN, Chloride Permeability

\section{Introduction}

India is the second largest cement producer in the world after China with a total capacity of 151.2 Million Tonnes. Construction industry plays a vital role to meet the requirements of the globalization. Concrete is a durable and versatile construction material. High performance concrete is a concrete, which possess high durability and high strength when compared to conventional concrete. High performance concrete contains more than one cementitious material such as fly ash, Silica fume or ground granulated blast furnace slag and usually a super plasticizer. Permeability is a vital property with respect to the sturdiness of concrete. The movement of water or alternative fluids through concrete typically conjointly carries aggressive agents that produce numerous sorts of sturdiness issues for concrete construction. In fact, permeability dictates the speed at which aggressive agents like gases $\left(\mathrm{CO}_{2}, \mathrm{SO}_{3}\right.$, etc.), liquids (acid rain, sea water, sulphate rich water, salt-bearing snow/water, ground water, etc.), penetrate into the concrete. This results in numerous sorts of chemical reactions. Corrosion damage to a concrete would occur if chloride salts penetrate the concrete cover and reach the reinforcing steel. Low permeability concrete is required to safeguard such concrete structures from penetration of aggressive chemicals into concrete. HPC appears notably helpful for defense against corrosion of reinforcing steel thanks to its low diffusivity and low permeability. These two favorable properties are usually achieved through HPC by the utilization of a low watercementitious materials ratio (W/C) and by adding silica fume, fly ash, or slag.

\author{
Dr. Vaishali. G. Ghorpade
}

Dr. Beulah. M

The practice of using supplementary cementitious materials in concrete mixtures has been growing globally. Fly ash is the most widely used supplementary cementitious material in the concrete which is obtained from thermal power plants. The quality of fly ash to be used in the Portland Pozzolana cement is covered under IS 3812:1981. Silicafume is extremely fine with particles less than $1 \mu \mathrm{m}$ in diameter and with an average diameter of about $0.1 \mu \mathrm{m}$, about 100 times smaller than average cement particles. Because of its extreme fineness it is a very efficient pozzolanic material. Metakaolin is a high quality pozzolanic material, which is blended with Portland cement in order to improve the durability of concrete and mortar. The effect of these supplementary cementitious materials affects the degree of influence on the freshly mixed concrete.

Addition of these mineral admixtures not only reduces the cement content in concrete but a durable concrete by reducing the permeability and also improving the resistance against chloride attack, acid attack, abrasion, freezing and thawing and fire resistance. Fire behavior of HighPerformance Concrete Made with Silica Fume at Various Moisture Contents studied by Nin chan [1999]. Influence of pozzolan from various by-product materials on mechanical properties of high-strength concrete was explained by Vanchai Sataa[2007].

The artificial neural network (ANN) models are extensively applied to varied relevant infrastructure engineering areas like geotechnical engineering, water resources and coastal engineering. Artificial neural networks are a typical modern interdisciplinary subject that helps in solving various different engineering problems which could not be solved by the conventional modeling and statistical methods. Artificial neural networks (ANNs) are a functional abstraction of the biologic neural structures of the central nervous system. (Aleksander and Morton, 1993; Rudomin et al., 1993; Arbib, 1995; Anderson, 1995). In neural network model the number of parameters has to be predefined before the beginning of the training. These parameters determine the success of the training. Therefore combining genetic algorithms with neural networks (GANN), the genetic algorithm is used to find these parameters. The feed-forward networks with back propagation learning have drawn more attention among researchers, especially in the GANN field. From a mathematical point of view, feed-forward neural network is a function. It takes an input and produces an output. The input and output is represented by real numbers. Back-propagation is one method to train the network [Rumelhart, 1986]. It is a very reliable; however a little bit slow training strategy. The training is performed by one pattern at a time.GA also has its own shortages such as lower local convergence, speed linking to premature convergence etc. 


\section{Literature Survey}

Hong-Sam Kim et al. [2007] studied durability of concrete using Silicafume (SK) and Metakaolin (MK). Collepardi et al. [2004] compared the effect of the addition of mineral admixtures ( $F A$, slag and ground limestone) as partial replacement of Portland cement on the $\mathrm{CO}_{2}$ penetration rate and found that addition of mineral admixture increases the carbonation rate in concretes.

Kartini et al [2010] through experimental results suggested that replacement of ordinary Portland cement (OPC) with $R H A$ reduces the permeability of concrete. Xu et al. [2010] heated the PFA concrete and investigated the mechanical and durable properties of concrete. Vinay Chandwan[2014] developed a model for slump of ready mix concrete using genetically evolved artificial neural networks. Vinicus Veloso [2014] studied on the compressive strength of high performance concrete by using kazien programe.

\section{Research Aim and Scope}

The aim of present research is to study the influence of the different mineral admixtures at various water- binder ratio and aggregate binder ratio on the permeability of high performance concrete.

In the structure of the present study an ANN model has been generated with the experimental data for predicting the permeability of high performance concrete.

\section{Iv. Materials and Methodology}

\section{A. Materials}

The cement used in the experimentation was 53-grade ordinary port land cement and having a specific gravity of 3.15 which satisfies the requirements of IS: 12269-1987 specifications. The crushed granite aggregates $(20 \mathrm{~mm}$ down) were collected from the local quarry. and tested as per IS: 2386-1963 (I, II, and III) specifications. Locally available sand collected from the bed of river was used as fine aggregate. The sand used was having fineness modulus of 2.96 and conformed to grading zone-III as per IS: 383 1970 specification. The mineral admixture Metakaolin was obtained from the 20 MICRON LIMITED company at Vadodara in Gujarat. The Metakaolin was in conformity with the general requirements of pozzolana. Silica fume used in the present study was obtained from the Elkem India Pvt Limited, Mumbai. Fly ash belonging to class-F obtained from Rayalaseema Thermal Power station (RTPS), Muddanuru was used in the present investigation. To impart additional desired properties, a super plasticizer (Conplast SP-337) was used.

\section{B. Methodology and Model Development}

The main objective of this research is to develop a neural network model for predicting the permeability of high performance concrete. Experiments was conducted to determine the permeability of High performance concrete after 28 days curing with various parameters like watercement ratio $(0.3,0.325,0.35,0.375,0.4,0.425,0.45,0.475$ $\&$ 0.5), aggregate-binder ratio $(2,2.5)$ and percentage replacement of mineral admixtures $(0,10,20 \& 30 \%)$. A total of 180 HPC mixes were cast in the laboratory for permeability test. Out of these 180 data sets, 165 data sets are utilized for training the network and 15 sets for validation of network model.

The proposed system targets to design a framework for forecasting the permeability of the high performance concrete considering Metakaolin, Silicafume and Flyash as the prime constituent in it. This should interpret that the proposed framework should have the potential to forecast the permeability of the high performance concrete considering the given set of values e.g. Water to Binder Ratio (W/B), Aggregate to binder ratio (A/B), Type of MA $\left(\mathrm{T}_{\mathrm{MA}}\right)$, and percentage replacement of admixtures (\%MA).

Thus, the input vector selected for this network model is

$$
\mathrm{X}=\left\{\mathrm{W} / \mathrm{B}, \mathrm{A} / \mathrm{B}, \mathrm{T}_{\mathrm{MA}}, \% \mathrm{MA}\right\}^{\mathrm{T}}
$$

The network is expected to establish the degree of nonlinearity through examples presented in an implicit manner, during training. The proposed framework should forecast the permeability $\left(\mathrm{P}_{\mathrm{HPC}}\right)$ for the given input values. Accordingly, the output vector for the neural network model is selected as

$$
\mathrm{Y}=\left\{\mathrm{P}_{\mathrm{HPC}}\right\}^{\mathrm{T}}
$$

The input and output parameters have been normalized in the range $(0,+1)$ using suitable scaling factors.

The structure of network is illustrated in terms of set viz. (i, $\mathrm{h}_{1}, \mathrm{~h}_{2}, \mathrm{~h}_{3}, \ldots . . \mathrm{h}_{\mathrm{n}}, \mathrm{j}$ ), where $i$ represents the quantity of neurons in the input layer, $h_{n}$ is the quantity of neurons in the $\mathrm{n}^{\text {th }}$ hidden layer and $j$ represents the quantity of output neurons. The proposed work considers 4 input nodes that directly corresponding to the four inputs (viz. Water to Binder Ratio, Aggregate to binder ratio, Type of MA, and percentage replacement of admixtures) and an output layer consisting of 1 node corresponding to permeability factor. Therefore, the network structure for the current issue is (4, $\left.\mathrm{h}_{1}, \mathrm{~h}_{2}, \mathrm{~h}_{3}, \ldots \ldots, \mathrm{h}_{\mathrm{n}}, 1\right)$. The amount of hidden layers can be varied in future but currently it is fixed to 10 . The amount of neurons in each hidden layer can also be varied. The authentic quantity of hidden layers and amount of neurons in each hidden layer can be found on trial and error basis in the preliminary training process. To start with, a configuration of 4-7-1 has been tried for the proposed neural network model. In subsequent trails, the amount of neurons in hidden layer is increased from 7 to 10 . The performance of these four networks has been observed after two hundred training epochs. It is observed that the RMS error for 4-10-1 configuration is reducing progressively after each training epoch. Accordingly a configuration of 4-10-1 has been selected for GA / ANN model. The architecture is shown in Fig: 1.

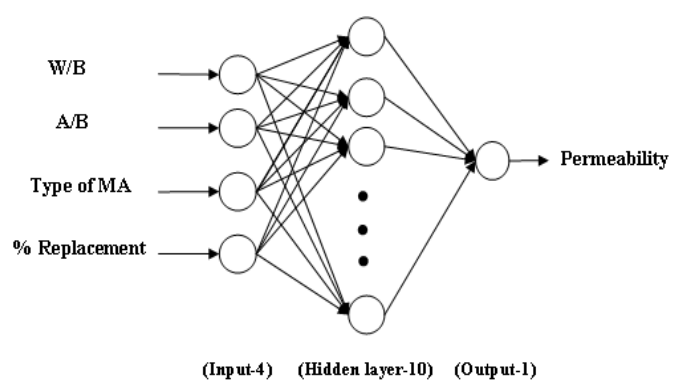

Figure 1. Final Architecture of GA/ANN Model for Permeability 
The network configuration chosen for the present work is $4-10-1$. Therefore, the numbers of weights (genes) that are to be determined are $4 \times 10+10 \times 1=50$. With each gene being a real number, and taking the gene length as 5 , the string representing the chromosomes of weights will have a length of $50 \times 5=250$. This string represents the weight matrices of the input-hidden layer-output layers. An initial population of chromosomes is randomly generated. Weights from each chromosome have been extracted using the genetic algorithm implemented in Matlab. A constant learning rate of 0.5 and a momentum factor of 0.8 have been adopted during the training. Satisfactory training has been obtained after just 900 training cycles. The progress of the learning of the network is monitored for every 100 training cycles. The RMS error after 900 cycles is 0.0000454552 . Visualizing this scale of RMS error, it can be said that the performance of the experimented network is satisfactory and therefore training phase is aborted in order to avoid over training. Usually, over training is avoided in order to protect the generalization potential of the proposed network. The proposed network is also evaluated with respect to the computational ability of the throughout preciseness. Usually training using large training set is avoided and expected results are scrutinized for the best throughput value for estimating the effectiveness of the optimal results for minimizing the processing time and enhance the computational ability. The training of the network accepted at this stage is presented in Fig: 2

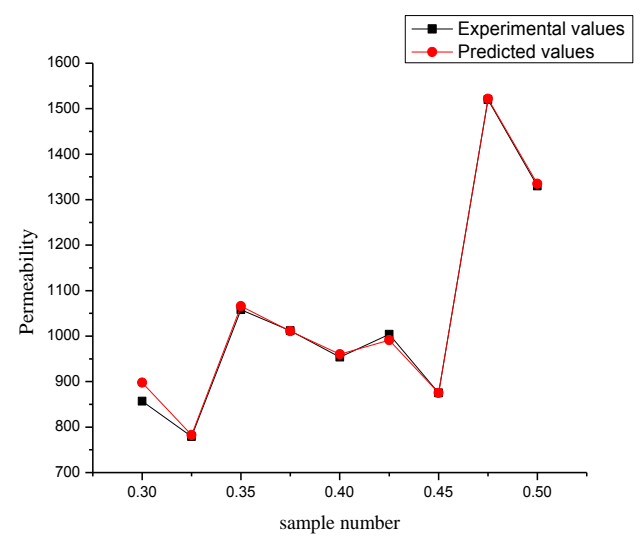

Figure 2. Learning of GA/ANN Model for Permeability

Although, the network has successfully derived the complex relationship between the input values and the permeability of HPC, it must be tested for new problems outside the training set for its practical use as a proposed GA/ANN model. After successful training of the network, it is expected to have mapped the desired bond between the various input and output parameters. The network should also be able to generalize this connection for its application for new issues. This validation of the proposed network model has been done in the current study by signifying the network with new issues within application domain. It may be noted here that this current network model is valid for the application domain as bounded by the scaling factors.

The validation of the GA/ANN model for permeability of high performance concrete is presented in Fig:3 which clearly depicts the excellent performance

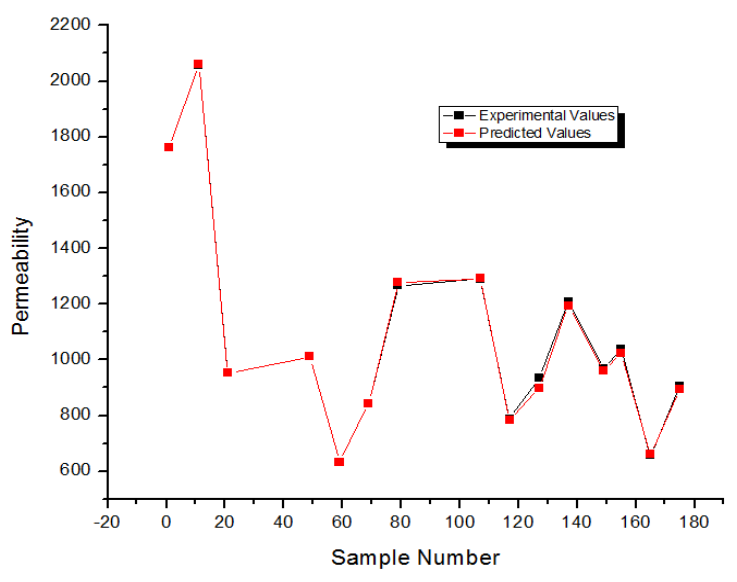

Figure 3. Validation of GA/ANN Model for Permeability

\section{v. Conclusion}

In this paper, a novel method for predicting the permeability of High performance concrete has been demonstrated. The Genetic Algorithm based neural network model has been trained using 165 examples obtained from experimental results. The training examples are so chosen that they will cover all the variables involved in the problem. The weights for the network have been attained using a genetic algorithm. The network could learn the prediction of permeability with just 900 training cycles. After successful training, the GA based neural network model is able to predict the permeability of high performance concrete satisfactorily for new problems with an accuracy of about $95 \%$.

\section{References}

[1] Anderson.J.A, Arbib.M.A" Handbook of brain of brain theory and neural networks"Cambridge MA:MIT press, 1995.

[2] Hong-Sam Kim. Sang-Ho Lee, Han-Young Moon "Strength properties and durability aspects of high strength concrete using Korean metakaolin"Construction And Building Materials 21(6):12291237 - June 2007.

[3] I. Aleksander \& H. Morton,A review of: "Neurons and Symbols: The Stuff That Mind is Made Of" 1993 London: Chapman \& Hall.

[4] K..Kartini, H. Mahmud, and M. Hamidah, "Absorption and Permeability Performance of Selangor Rice Husk Ash Blended Grade 30 Concrete,"Journal of Engineering Science and Technology, vol. 5, 2010, 1-16.

[5] LIU, X and M H Zhang, "Permeability of High-Performance Concrete Incorporating Presoaked Lightweight Aggregates for Internal Curing". Magazine of Concrete Research, 62, no. 2 2010: 79-89.

[6] M. Collepardi, S. Collepardi, J. O. Olagot, and F. Simonelli, "The influence of slag and fly ash on the carbonation of concrete," in Proc. of 8th CANMET/ACI Int. Conf. on Fly Ash, Silica Fume, Slag, and Natural Pozzolans in Concrete, held May, 2004,23-29.

[7] Ni Hong-Guang, Wang Ji-Zong "Prediction of Compressive strength of concrete by neural networks "Cement and Concrete research-Cem. Concr. Res.volume 30,2000:1245-1250.

[8] Rumelhart,D.E., Hinton,G.E., \& Williams, R.J.”.Learning internal representations by error propagation", 1986,Chap.8,.318-362.

[9] Sammy Yin Nin Chan, Gai-Fei Peng, and Mike Anson "Fire Behavior of High-Performance Concrete Made with Silica Fume at Various Moisture Contents" 96,3, 1999,pp: 405-409

[10] Vanchai Sata ,Chai Jaturapitakkul, Kraiwood Kiattikomol "Influence of pozzolana from various by-product materials on mechanical properties of high-strength concrete" Construction and Building 
Proc. of Fourth International Conference On Advances in Civil, Structural and Mechanical Engineering - ACSM 2016

Copyright (C) Institute of Research Engineers and Doctors, USA .All rights reserved.

ISBN: 978-1-63248-096-5 doi: 10.15224/ 978-1-63248-096-5-09

Materials , Elsevier, Volume 21, Issue 7, July 2007, Pages 1589-

1598.

[11] Vinay Chandwani Vinay Agrawal Ravindra Nagar Sarbjeet Singh "Modeling Slump of Ready Mix Concrete Using Genetically Evolved Artificial Neural Networks" Advances in Artificial Neural Systems ,Volume 10,September 2014; 2014:1-9.

[12] Vinícius Veloso de Melo" Predicting high-performance concrete compressive strength using features constructed by Kaizen Programming" Brazilian Conference on Intelligent Systems, 2015.
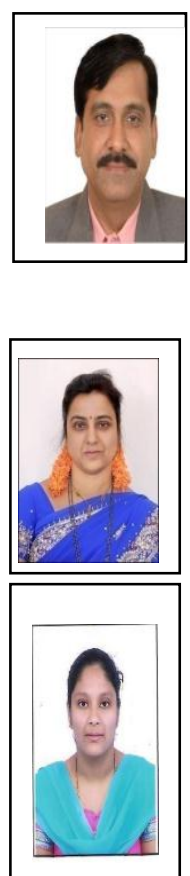

Dr. H. Sudarsana Rao is a professor in Civil engineering department and Director (ICS) JNT University, Anantapur, Andhra Pradesh, India. He has more than 30 years of teaching experience. He was awarded with best Professor award by the A.P. state Government in the year 2007. His research interests include Artificial Neural Networks, Fuzzy Logic, High-PerformanceConcrete, Fiber reinforced concrete etc., He is a Fellow of Institution of Engineers India and Life member of Indian Concrete Institute.

Dr.Vaishali G.Ghorpade is a professor in the Civil Engineering department .She has more than 15 of teaching experience. She has published more than 50 research papers in various National and International Journals. Her research interests include High-Performance-Concrete, Fibre reinforced concrete, admixtures etc. She is a life member of ISTE, MIE and Indian concrete Institute.

Dr. Beulah is an assistant professor in Christ University. Her research interests include Waste materials, Polymerization using waste materials, high-performanceconcrete, Artificial neural networks. 